the human brain-is not excluded from genetic laws and genetic diversity.

Dubinin published a new detailed article on the subject which appeared earlier this year in Voprosy Filosofii. It mostly repeated his earlier arguments, though it was more politicised. The ideas about the intellectual or spiritual aspects of human life became rather mystical, in spite of regular quotations from Marx, Engels and Lenin.

Through a complex of pseudoscientific argumentation, Dubinin tried to state that the intellectual and ethical progress of Homo sapiens humanis is properly directed in one social system only. In any other social system there is no progressive evolution. Social systems create the real man after birth; the priority of genes before birth is not questioned. Good systems create good persons, bad create bad. From Dubinin's autobiography it is clear that he considers himself a good man whose psychology and intellect has been developed under the influence of the best social systems. "I am thankful for my fate ... I do not want to live another life ..." $\mathrm{He}$ is happy. During his 70 years of life, he never discovered that 30 years of Stalinist terror were not good for the creation of Homo sapiens humanis.

There is, however, at least one important factor for securing the happiness of Homo sapiens logic-freedom to do research, whether genetic, social or political. Using his position as the director of the main Institute of General Genetics, his influence as Consultant on Biology for the Central Party Committee and his membership of different commissions and groups, Dubinin is working hard to suppress by all possible means the development of genuine research in the field of human genetics in the USSR. Even now the Soviet Union is not involved in many important fields of research in human genetics. As part of medical science, human genetics now has modest conditions for research into several specially selected problems, mainly associated with health programmes. But as a part of general biology, evolution research or population genetics, human genetics does not really exist in the USSR.

In a great country with more than a hundred national minorities, several different races and many different cultural roots, human genetics is probably too hot a science to handle.

\title{
ILL at ease
}

\section{Judy Redfearn finds out about neutron research at the Institut Laue-Langevin and talks to its director} WEUTRONS have long been re-
cognised as valuable tools for
research. Their importance is still
growing as new techniques are enabling
them to find new applications in
different branches of science. One of
the world centres for neutron research
is the Institut Max von Laue-Paul
Langevin (ILL) in Grenoble, France.
It is jointly run by Britain, France and
Germany, and this year, when it cele-
brates its tenth anniversary, has seen
the appointment of a British scientist
as its director.

$\mathrm{He}$ is Dr John White, a physical chemist from St John's College, Oxford, who took over from Professor R. Mössbauer, a German, last March. He faced a pressing problem after he took up his new post: what to do with spent fuel rods from the high flux reactor, the cornerstone of ILL's neutron facility. ILL has been assured of a fuel supply since President Carter lifted his ban on the export of enriched uranium, but the freeze on reprocessing caused some worries. Just last week, however, it was granted a licence to import 12 fuel elements into the USA for reprocessing at ERDA's Savannah River plant in Georgia.

But President Carter's policy is not the only factor which may influence ILL's future. The lifetime of the high flux reactor and the value of all ILL's facilities to its member states are now being assessed to determine the institute's long term prospeats after 1982 , the earliest date at whioh the three member countries could, under the original agreement, revoke their commitment. An extensive study of the reactor has shown that it may yet have 20-25 years more life in it-"a tribute", says Dr White, "to the French and German engineers who built it". If further studies support this, a report on the institute's future, due in the autumn, should give a firm assurance that the reactor will continue operating into the 1980 s.

How it will continue, however, is not yet certain. The report is expected to recommend whether or not it should go into a 'deuxième souffle'-a second stage involving the member states in another major investment to extend the facility's scope. Dr White believes that ILL will only survive into the 1980 s if instruments and techniques are constantly up-dated. "At the moment we have got world leadership in this area -and we have got to keep it up."

\section{A matter of satisfaction}

ILL's future success will depend, as it always has, on how well it satisfies its visiting researchers. Unlike many other laboratories and research organisations, it is essentially a users' laboratory. Some $70 \%$ of the neutron-beam time is available for outside experiments, mainly from universities and institutes in the three member countries but also from many other parts of the world. Only 400 staff, of which 70 are $\mathrm{PhD}$ scientists, are employed under fiveyear contracts to keep instruments running. ILL's Scientific Council considers approximately 700 experimental pro- posals each year; at its last meeting in March, it reported requests for twice as much experimental time as is available.

Experiments originating in the member countries are funded by the organisations, or Associates, which run the institute: the Science Research Council in Britain, the Gesellschaft für Kernforschung in West Germany, and the Commissariat à l'Enengie Atomique and the Centre National de la Recherche Scientifique in France. France and Germany signed the first intergovernmental treaty giving the goahead for the building of ILL in 1967 . It was not until 1973 that Britain, having abandoned an idea to build its own intense neutron source, joined in, paying a share of the original capital investment. Routine operation of the high flux reactor, which cost FF240 million of the FF335 million spent on building the whole institute, began in 1972. It has almost completed five years of successful operation and most of the instruments designed around it

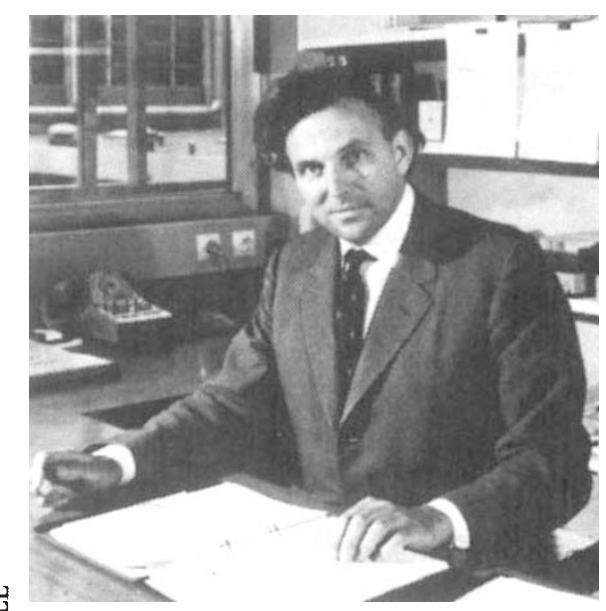

ILL's director, John White 
have now been working for $2 \frac{1}{2}$ years.

The high flux reactor is possibly the most intense continuous neutron source in the world at the moment. It operates at $57 \mathrm{MW}$ and contains a single fuel element of $9 \mathrm{~g}$ of $90 \%$ enriched uranium. Because such highly enriched uranium is contained within a small reactor core, the fission process is concentrated into a small volume and the resulting neutron radiation is very intense.

"If the first unique feature of this reactor is its high flux density", says Dr White, "the second is the interesting and varied sources of neutrons which surround the core". Neutrons straight from the reactor are all slowed down to thermal velocities as they pass through a vessel of deuterium at $300 \mathrm{~K}$. Those emerging from a particular part of the reactor are then speeded up by a piece of hot graphite to form a hot source. Other neutrons pass through liquid deuterium at $25 \mathrm{~K}$ and are slowed down even further to form a cold source. But perhaps the most important feature of ILL's reactor is the great increase in experimental area created by conducting some of the thermal and cold neutrons through special conducting pipes away from the space surrounding the reactor, which is crowded with instruments.

It is the ways in which they interact with matter that have made neutrons valuable research tools. Four properties make slow neutrons particularly useful in the study of liquids and solids: their electrical neutrality, short wavelength, low energy and magnetic moment. Because they have no electric charge they can penetrate the atom's electron shell and interact with the nucleus. Their short wavelength-of the same order as the atomic diameter-means that they are scattered by a regular array of atoms in a crystal to form a neutron diffraction pattern. Their low energy-of the same order as the quanta of vibrational energy of the scattering sample-means the dynamics of solids and liquids can be studied by

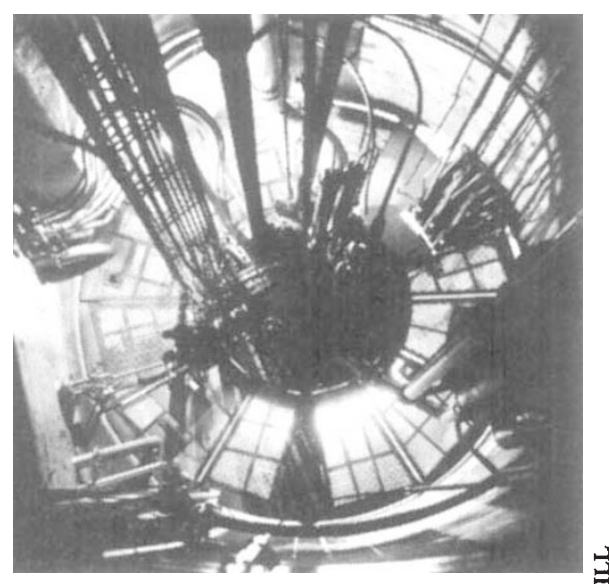

ILL's high flux reactor: view from the top measuring speed changes in the scattered neutrons. So called magnetic scattering occurs when the magnetic moment of the neutron interacts with an atom's magnetic moment; it facilitates the study of the magnetic properties of solids and liquids.

\section{Diversification}

Physicists were aware of the value of the neutron's properties 20 years ago when they started using them for studies in solid state physics. But it is only over the past ten years that they have been used in chemistry; and in the past three to four years they have found applications in biology as welllast year saw the first international conference on neutrons in biology. Dr White says that ILL's curious instrumentation has helped it to make a unique contribution in some of the new areas of science, particularly in polymer chemistry, biology and nuclear physics. The structure of biological materials, for example, can often be revealed in the diffraction patterns of neutrons scattered from them.

The phenomenon which makes neutrons so potentially valuable in chemistry and biology is called 'contrast'. It can best be explained by analogy with light. A glass rod immersed in a liquid will be clearly visible provided that the refractive index of the glass differs from that of the liquid. If the liquid's refractive index is changed to be the same as that of the glass, the rod will seem to disappear. Similarly, a biological material can be immersed in a mixture of heavy and light water whose refractive index with respect to neutrons is the same as parts of the material. Those parts of the material will then make no contribution to the neutron diffraction pattern and will have been 'contrasted' out. This means, for example, that a neutron diffraction pattern could be formed from, say, the RNA molecules inside a virus, no contribution to the pattern being made by any other part of the virus.

Dr White believes that the recent branching out into broader areas of science has come from a happy interaction between the interest of the users of ILL and the instrumentation that was already there. Britain added to the creative atmosphere by bringing many problems to be solved; the French and German approach had always been to design instruments to find new ways of working with neutrons. The two approaches combined well to bring forward an expansion in the use of neutrons for research. As Dr White puts it, "The French are a bit Cartesian, they tend to think mathematically; the Germans are Leibnitzian; and the British tend to be empirical". But he does feel that ILL gains rather than suffers from the fusion of these three different scientific temperaments.

The institute is assured of a supply of fresh ideas not only because so many different nationalities work together, but also because there is a regular turnover of permanent staff. Although the average age of the staff, 34 , means that ILL is a place for young people with good ideas, it does have one disadvantage. Each year the $2 \frac{1}{2}-3 \%$ net growth in ILL's budget allowed for by the Associates is gobbled up as the predominantely young staff moves up the salary scale, leaving very little for building new instruments.

"At the moment we are only building one or so instruments a year, which is hopeless because the normal amortisation rate for such heavily used instruments as those at ILL is 10 years at the most. At the present rate of building, instruments will be 15 years old or more before they can be replaced". Somehow, ILL is hoping to find a way of subsidising its budget so that more instruments can be built.

\section{Move under way}

A move in this direction is already under way. Since March, Dr White's main scientific concern has been in establishing a source of ultra-cold neutrons which are just energetic enough to reach a height of 15 feet in the earth's gravitational field. They are totally internally reflected from quite common materials and so can easily be trapped for experimentation.

Penhaps the most exciting application they could have is in the field of neutron optics. Existing techniques for focusing neutrons, for example, are as crude as the techniques used by Newton 300 years ago to focus light. As yet there is no neutron lens but the ultra cold neutrons travel so slowly that they can be focused with a magnetic field and could be used to develop neutronfocusing techniques. Already a highly coherent neutron beam has been produced at ILL. It is by no means a neutron laser, but it does have some of a laser's properties which could be useful in neutron optic studies.

"The people who come to ILL have got particular problems that can be solved no other way than by neutrons", says Dr White. "Even five years ago, we wouldn't have believed that neutrons would have the sensitivity to detect the things they now do; but with the high flux and the specialised instruments at Grenoble, we have seen hitherto unobservable things". When the spallation neutron source-a pulsed source of very hot neutrons just approved in Britain-is built at the UK's Rutherford Laboratory, he claims that Europe will house the world's most sophisticated neutron facilities. 